
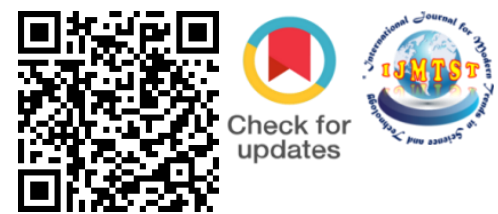

\title{
A Review on Cocoa Butter Alternatives in Chocolate Preparation
}

\author{
Writtika Das ${ }^{1}$ | Sweta Das ${ }^{2}$ I Shairee Ganguly ${ }^{3}$ | Dolanchapa Sikdar ${ }^{4}$ | Kakali Bandyopadhyay ${ }^{5}$ \\ 1,2: B. Tech. Students, \\ 3,4: Assistant Professor \\ 5: Associate Professor and HOD
}

Department of Food Technology, Guru Nanak Institute of Technology, 157/F, Nilgunj Road, Sodepur, Panihati, Kolkata 700114

\section{To Cite this Article}

Writtika Das, Sweta Das, Shairee Ganguly, Dolanchapa Sikdar and Kakali Bandyopadhyay, "A Review on Cocoa Butter Alternatives in Chocolate Preparation", International Journal for Modern Trends in Science and Technology, Vol. 07, Issue 01, January 2021, pp.- 15-140.

\section{Article Info}

Received on 11-December-2020, Revised on 30-December-2020, Accepted on 06-January-2021, Published on 19-January-2021.

\section{ABSTRACT}

Cocoa butter naturally occurs in cocoa bean. It is present about 50\% of cocoa nib. It is highly resistant to oxidation due to presence of high level of natural tocopherol. It is brittle at room temperature and its melting point is between $34^{\circ} \mathrm{C}$ to $38^{\circ} \mathrm{C}$. But, cocoa butter is expensive and its price is subjected to large fluctuations. That's why some alternatives for cocoa butters are produced, such as cocoa - butter equivalents (CBEs, like from enzymatic inter-esterification of tea seed oil and fatty acid methyl esters), cocoa-butter substitute (CBSs, esterifies propoxylatedglycerin containing acyl groups derived from saturated linear fatty acids, at least 50 moles percent of the total acyl groups are used) and cocoa-butter replacers (CBRs, like evaluation of milk fat fractional and modified techniques for making CBR.) Their composition according to triglycerides, fatty acids, sterols and other unsaponifiable components are discussed in this paper. Coconut oil, non-lauric contained fats like palm oil, soybean oil, rapeseed oil, can be used as replacer. These alternatives have various advantages; it improves fat stability, reduces fat migration, and incorporates softness to the product. As the alternatives do not require tempering, it is easier to achieve glassy texture. This work reviews on the theory of the compositional data of vegetable oils, and fats which are used as cocoa-butter alternatives in the production of chocolate.

KEYWORDS: cocoa butter alternatives, melting point, chocolate

\section{INTRODUCTION}

\section{Cocoa bean (CB) is the fatty seed found inside a} cocoa pod, fruit of the

Theobroma cocoa plant. It is a small evergreen tree that belongs to the family Malvaceae. There are several processes which undergo the preparation of cocoa butter. It is brittle in Temperature below $25^{\circ} \mathrm{C}$ soften in hand and melts in mouth having a temperature of about $34^{\circ} \mathrm{C}$ [33]. Cocoa butter has several advantages which makes it the main ingredient saturated fat and less amount of caffeine and theobromine. It also contain some vitamins in the soluble form such as vitamin $\mathrm{E}$ in the form of beta - tocopherol, alpha - tocopherol and gamma - tocopherol. Among all this form of tocopherol,only beta - tocopherol is used for 
chocolate preparation, because it has a high melting point . This beta - tocopherol gives an excellent smoothy and silky texture to the chocolate. But nowadays cocoa cultivation has reduced to a wide range. Scientists are searching for replacements for cocoa butter from cocoa beans due to its raise of high price. Recent studies have shown that cocoa beans contain a little amount of cocoa butter. So,the replacements of cocoa butter with other vegetable oils have been replaced. The findings highlights how these cocoa butter alternatives are being produced either by blending ,modifying the natural oils or fats from palm oil[16] palm kernel oil ,mango seed kernel fats, kokum butter fat, sal fat, Shea butter and illepe fat.

Some alternatives used are like: CBEs ( cocoa butter equivalents, have been designed to approximately the composition of cocoa butter so that they can replace cocoa butter in any proportion. It is a special triacylglycerol structure that gives cocoa butter and it's equivalents their unique melting points. A cocoa butter equivalents must be compatible with cocoa butter i.e. it must be complete soluble in solid phase. Thus it must have similar physical, chemical and polymorphic behaviour.[29]

CBR (Cocoa butter replacer) was prepared by enzymatic

interestification[30][23] of hydrogenated and solid fraction (SF) of tea seed oil from THERMOMYCES lanuginosusin dark chocolate. Supercritical carbon dioxide ( SC -CO2) extraction and fractional of palm kernel oil from palm kernel as cocoa butter replacers blend .

---- The palm kernel oil (PKO) was extracted from palm kernel at $40^{\circ} \mathrm{C}$ and $80^{\circ} \mathrm{C}$ and pressure from 20.7 to $48.3 \mathrm{MPa}$ with a flow type apparatus. Much shorter chain and longer chains are extracted by processing.

\section{A flowchart of how cocoa butter is prepared}

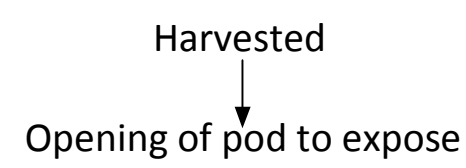

beans

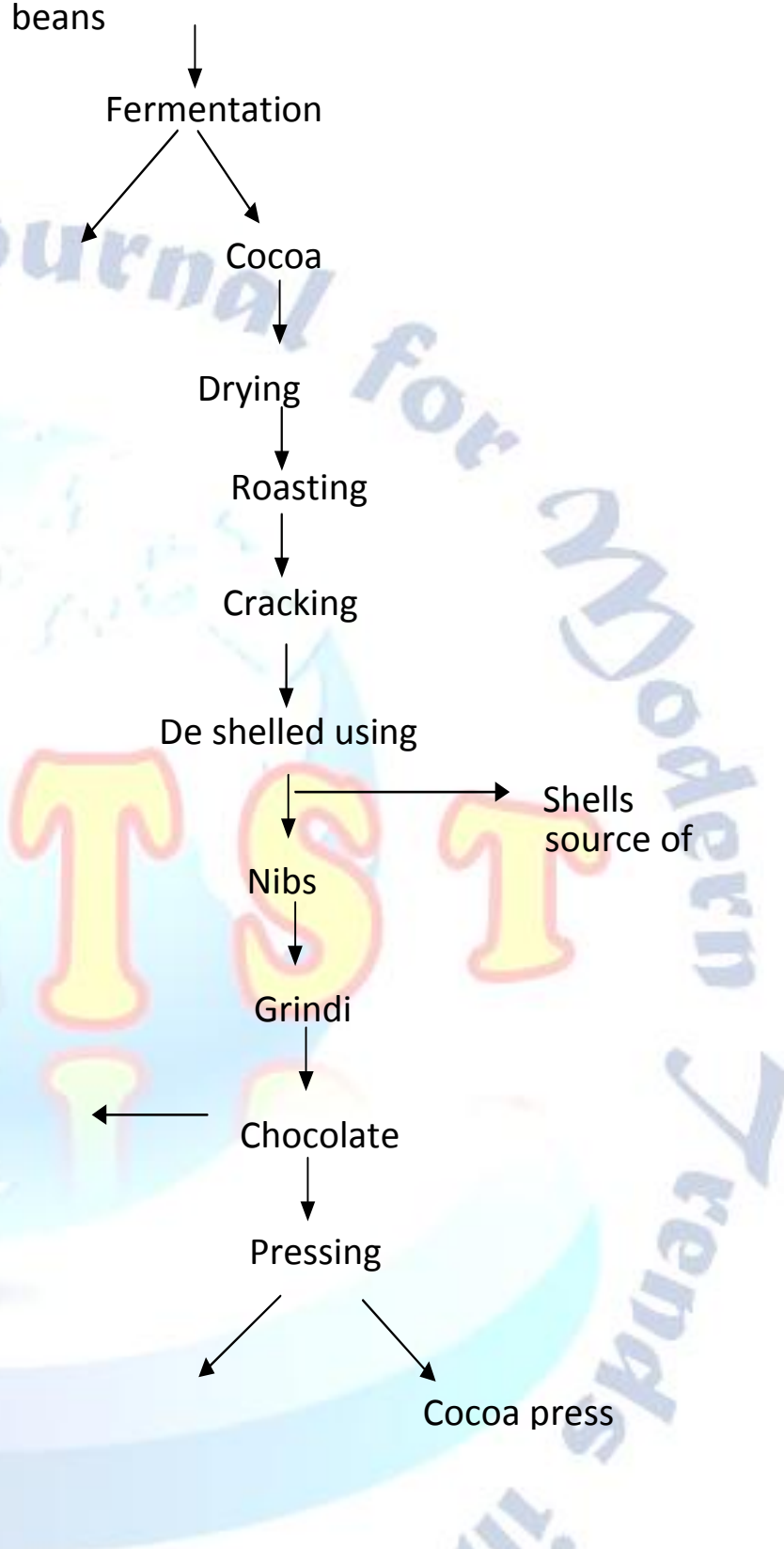

\section{PRODUCTION OF COCOA BUTTER}

Cocoa-butter also called Theobroma oil, is a pale yellow and edible vegetable fat extracted from the cocoa bean. It is used to make chocolate, as well as some ointments, toiletries, and pharmaceutical. [2]

Cocoa-butter has a cocoa flavour and aroma. Its melting point is just below human body temperature.

Cocoa-butter is obtained from whole cocoa beans. For use in chocolate manufacturing, the beans are fermented before being dried. The beans are then 
roasted and separated from their hulls to produce cocoa-nibs. [3] [35]

About $54-58 \%$ of the cocoa-nibs are cocoa butter. The cocoa nibs are ground to form cocoa mass, which is liquid at temperatures above the melting point of cocoabutter and is known as cocoa liquor or chocolate liquor. Chocolate liquor is pressed to separate the cocoa-butter from the non-fat cocoa solids [4]. Cocoa-butter is sometimes deodinized to remove strong or undesirable tastes [1] [5] [29].

\section{COMPOSITION OF GENUINE COCOA BUTTER}

A. Fat composition:

Total saturated fats: - 57-64\%

Stearic acid (24-37\%)

Palmitic acid (24-30\%)

Myristic acid (0-4\%)

Anachidic acid (1\%)

Lauric acid (0-1\%)

Total unsaturated fats: - $36-43 \%$

Monosaturated fats: - 29-43\%

Oleic acid (29-38\%)

Palmitoleic acid (0-2\%)

Polyunsaturated fats: - $0-5 \%$

Linoleic acid (0-4\%),

Alpha linoleic acid (0-1\%)

Cocoa butter contains a high proportion of saturated fat as well as monosaturated oleic acid, which typically occurs in each triglyceride. The predomenon triglycerides are POS, SOS, POP, where $\mathrm{P}=$ palmic, $\mathrm{O}=$ oleic, $\mathrm{S}=$ stearic acid residues.[6] [7] [8] [9] . Cocoa butter, unlike non-fat cocoa solids, combines only traces of caffeine and theobromine [10] [31].

\section{TYPICALLY FATTY ACID COMPOSITION (\%)}

Arachidic acid $(\mathrm{C} 20: 0)=1.0 \%$

Linoleic acid $(\mathrm{C} 18: 2)=3.2 \%$

Oleic acid $(\mathrm{C} 18: 1)=34.5 \%$

Palmitic acid $(\mathrm{C} 16: 0)=26.0 \%$

Palmitoleic acid $(\mathrm{C} 16: 1)=0.3 \%$

Stearic acid $(\mathrm{C} 18: 0)=34.5 \%$

Other fatty acids $=0.5 \%[11]$

\section{PROPERTIES OF COCOA-BUTTER}

Cocoa butter (CB) is the byproduct of cocoa bean processing industry and is obtained from the mature bean from the Theobroma cocoa plant. For chocolate production, cocoa butter is an essential product and it is also used in other confectionery industries. It has a unique physiochemical property and it is valued for this property and this property is observed due to its peculiar fatty acid composition. The major part of it is tryglycerols (TAOS), present in CB in a symmetrical formation and it also contains very less amount of highly unsaturated fatty acids . Cocoa butter has a sharp melting point ranges from $27-35^{\circ} \mathrm{C}$. At room temperature, it becomes very hard and brittle[34].This hardness depends on the solid fat content. The nature of the crystalline solids lattice affects the hardness of the cocoa-butter. Physiochemical properties of $\mathrm{CB}$ are described below as points. The degree of unsaturation is indicated by the iodine value and the cocoa butter having higher iodine value is soften than the lower iodine value. The saponification value indicates the average chain length of fatty acids present in fat. If the saponification value of the fat is high then the chain length of the fatty acids will be shorter and vice-versa. The acid value (v) is defined as the weight in milligrams of potassium hydroxide necessary to neutralize the free fatty acid in $1 \mathrm{~g}$ of fat and it is used to quantify the free fatty acids present in fats or oils. The cloud point (CP) is related to the unsaponification of oil. If the unsaturation of oil is higher,then the CP is low.

PHYSIO-CHEMICAL PROPERTIES OF COCOABUTTER(RANGES SHOW THE VARIATION FROM REGION TO REGION)

Iodine value $(\mathrm{g} 12 / 100 \mathrm{~g})=32-35$

Saponification value $(\mathrm{mg} \mathrm{KOH} / \mathrm{g})=192-199$

Acid value $(\mathrm{mg} \mathrm{NAOH} / \mathrm{g})=1.04-1.68$

Peroxide value $(\mathrm{meq02} / \mathrm{kg})=1.00-1.10$

Melting point $=29-40^{\circ} \mathrm{C}[18]$

\section{COCOA-BUTTER ALTERNATIVES (CBAS)}

+ Cocoa-butter is an important ingredient in chocolate manufacturing. But due to the uncertainty in availability and higher price in the market, industries are looking for some alternatives of cocoa butter that is called cocoa butter alternatives (CBAS). CBAs are kind of fats that are able to fulfill the function of cocoa butter completely on its parts. On the basis of functional differences in the vegetable fats added to chocolate( CBAs ) are to be distinguished and are labeled as cocoa butter replacer (CBRs) , cocoa butter equivalents (CBEs) and as cocoa-butter substitutes (CBSs) \{Brinkmann, 1992:Bollschotte, 1994\}[19] . 
All types of fats are used as a replacement of cocoa-butter partially or fatty acids in chocolate or in other confectionery industries are specially known as the CBRs. \{Kheini198:\}

CBRs are generally cheaper than CB and serve almost all the purpose of $\mathrm{CB}$. It can also be processed just like cocoa-butter and meet specific country legal requirements such as use of non- animal and non-synthetics fats in chocolate products (MC Ginley, 1991). The fatty acid composition of cocoa butter replace is almost similar to that of cocoa-butter with more or less same glycerides structure. CBRs can be divided into two groups which are also used as cocoa-butter replaces in chocolate manufacturing that is - : cocoa-butter equivalents (CBEs) and: cocoa-butter substitutes (CBSs).

\section{COCOA-BUTTER ALTERNATIVES ----.}

(1) Cocoa butter substitutes eg. Coconut oil, palm oil

(2) cocoa-butter replacer eg. soyabean oil, rapeseed oil,

(3) kernel oil [14] [27].

\section{-- 3a) cocoa-butter extender (CBEX) COCOA-BUTTER REPLACER}

It is an alternative fat formulated from fractional vegetable fats can be used to impart glass retention and sharp meltdown to the final products without tempering and has a high tolerance (upto 20\%) for cocoa-butter. Cocoa-butter replacer can be mixed with cocoa liquor to produce a compound chocolate rich in cocoa taste. Cocoa-butter replacer are mainly used in compound coatings, due to certain compatibility with cocoa-butter, $\mathrm{CBR}$ can be used in combination with cocoa-butter to give compounds suitable for both coatings and moulding. These fats are all of non-lauric region so there will be no rise about the soapy taste in the finished product. The most important thing is compound made with CBR do not need tempering[22]. This time of products include a low trans content and zero trans replacers which are non- lauric, nontempered,hardened and fractionated speciality fats inheriting similar sensory and heat stability as that of cocoa-butter[17] [28].

\section{Cocoa Butter equivalents (CBEs)}

Cocoa butter equivalents are used in place of $\mathrm{CB}$ due to its availability and low price. The products used as (CBEs) are palm oil [25] palm mid-fraction and related products, illipe (Shoreastemoptera) fat,Shea butter, sal fat ,kokum butter etc .

CBEs are vegetable fats, they have similar physical and chemical properties just like CB. That's why they can be mixed with CB in any amount without altering the melting, repeo-logical and processing characteristics of the final products like CB. CBEs contain a glyceride composition similar to that of $\mathrm{CB}$ and the properties of its composition are almost similar to that of $\mathrm{CB}$ and compatible with $\mathrm{CB}$ in mixture for chocolate manufacturing. CBEs contain some of major fatty acids like palmitic acid[24] stearic acid and oleic acid, similar to that of $\mathrm{CB}$ and $\mathrm{CBEs}$ are made of generally by blending of different mixture,of palm oil ,illipe etc which have been said above. It contains approximately $40 \% 1$ - palmito , 2-olein ,3-sterin, glycerol ,27\% of 1,3 distearimmonoleate glycerol and $21 \%$ of $1-3$ dipalmitin-2monooleate glycerol and minor amount of other triglycerides. CBEs are divided into two subgroups - (1) CBEX and (2) CBIs .CBEX can't be mixed with $\mathrm{CB}$ in any amount but CBIs contains the property similar to $\mathrm{CB}$ and it also contains solid triglycerides. That's why it is used to improve the softness of cocoa-butter [31].

\section{COCOA BUTTER SUBSTITUTES}

Cocoa butter substitutes are another replacer of $\mathrm{CB}$ in chocolate production. CBSs are fats which can be mixed with $\mathrm{CB}$ in a limiting amount without altering the melting, physiological properties and processing properties. They do not necessarily have physio-chemical characteristics like $\mathrm{CB}$ and vegetable fat blends. The degree of compatibility basically depends on the quality. It contains lauric and myristic acids and some physical characteristics similar to $\mathrm{CB}$. But they are chemically different so CBSs are used for whole replacement of $\mathrm{CB}$. The blending of mango kernel fat is also used as CBS in production of cocoa butter [15] [32].

\section{SOME ADDITIONAL ADVANTAGES OF CBAs}

There are several healthy effects of using CBA-

(A) Cocoa-butter can improve the skin, and it may have anti-inflammatory and anti- oxidizing effects. 
(B)Cocoa-butter is a common active ingredient in lotions, creams, and lip balms.

(C)Pure cocoa-butter is edible and it contains a mixture of mono- unsaturated and saturated fats and few nutrients. According to the United States department of agriculture (USDA), one table spoon (tbs) of 13.6 gms of cocoa-butter has the following nutritional Cocoa-butter also contains some amount of vitamin $\mathrm{E}$ and vitamin $\mathrm{K}$.

Beside this, cocoa-butter is high in fatty acids, which is why it's often touted fat its ability to hydrate and nourish the skin and improve elasticity. The industries find the fat in cocoa-butter forms a protective barrier over skin and hold in moisture. It is also rich in nutrients plants compound called photochemicals, improve the blood flow to the skin and protect the skin from sun's harmful UV RAYS.

Cocoa-butter alternatives are used as $\mathrm{CB}$ replacement because they are available at low prices. Its physical properties are almost similar to CB. So it is a very important ingredient in chocolate manufacturing and it has also nutritional value like $\mathrm{CB}$.

\section{CONCLUSION}

Cocoa-butter is an important and valuable fat in chocolate production and in any confectionery industries or other products. Cocoa tree should be cultivated in a few countries to grow up the supply of cocoa-butter in chocolate industries. Cocoabutter contains a huge amount of nutritional value. People can use it to fulfill the different kind of needs. But due to the unavailability in the market and high price, Industries find some cocoa-butter alternatives (CBA) at low cost .CBRs, CBEs and CBSs have the physical properties closer to CB .CBAs like palm oil, sal, mango seed kernel etc helps in introducing the fats of nontimber forest. CBAs are by the blending of these products in different way or by modifying biocatalyst or chemical catalyst in an optimized condition with different solvent system. So above all, $\mathrm{CB}$ is a unique that is so essential in chocolate[21] and its alternatives too. But if it is noticed that CBAs are sometimes unable to fulfil the exact demand and entity of cocoa-butter. So more works and researches are still needed in this production.

\section{ACKNOWLEDGEMENT}

The authors are hereby acknowledging the Honourable Managing Director of JIS Group for financial support and inspiration.

\section{REFERENCES}

[1] “COCOA BUTTER AMOUNTS CONVERTER”. Convert-to.com . Retrieved 3 November 2016.

[2] "COCOA BUTTER "EncyclopaediaBritannica.july 1998. Retrieved 10september 2007 .

[3] Industrial chocolate manufacturing and use ,4rth Edition ,edS.T.Beckett, Chapter 12,G .Talbot .

[4] Cocoa-butter pressing the Grenada chocolate company.Archieved from the original on 6 October 2007.

[5] The Nibble." The world's best white chocolate page 3: Percent cacao@cocoa butter “. Retrieved 3march 2009.

[6] Lonchampt,P;HartelRichard,W.(2004) ."Fat bloom in chocolate and compound coatings" . European Journal of Lipid Science and Technology.106(4):241-274.Doi: $10.1002 /$ ejlt. 200400938.

[7] "Composition of the cocoa bean ".

Hershey centre for health and nutrition.

Retrieved 20 November 2012.

[8] Liendo,Rigel;Padilla,DannyC.; Quintana,Agricia(November 1997).

"Characterization of cocoa-butter extracted from Criollo cultivars of TheobromacacaoL".

[9] EL SAIED ,Hani M:Morsi,M.K; Amer, M.M.A(June 1981).

[10] "USDA NUTRIENT DATABASE" -5OCTOBER 2016.archieved fr the original on $3^{\text {rd }}$ March 2015 retrieved 3november 2016 taken on $11^{\text {th }}$ August 2019 .

[11] Frank Jill (24october2014)"cocoa butter alternatives in chocolate.

[12] Thomas,Alfred (2002)."Fats and fatty oils" .Ullmannsencyclopaedia of industrial chemistry.

[13] "cocoa butter prices, bean futures soar"www.foodbusinessnew.net

[14] cocoa-butter alternatives from www.google scholar.com

[15] Nestle Research Centre ,Vers -ches-les-Blancc , Lausanne, Switzerland. Publication date 2004 March 16.

[16] Journal of Oil Palm Research 30(4) 537-547, 2018

[17] BinduNaik, V Kumar J BioresourseEng Technol2 1-11, 2014.

[18] SheidaKadivar, Nathalie De Clercq, Davy Van de Walle, Koen Diwettink. Journal Of The Science Of Food andAgriculture 94(7),1325-1331,2014.

[19] Journal of the American Oil Chemists' Society 91(1), 39-48, 2014

[20] Stuart Dale Beckett's Industrial Chocolate Manufacture and Use ,479-491, 2017

[21] Zeng Zhang, Jia Song, Wan Jun Lee, XiadongXie,YongWang.Food Chemistry 126518,2020.

[22] Emmanuel OheneAfoakwa,Aliester Paterson, Mark Fowler. Trends in Food Science And Technology 18(6),290-298, 2007.

[23] Edmand J Wilson, J Jhon Pease . Proceedings on the world conference on palm and coconut oils for the $21^{\text {st }}$ century. Sources, Processing, Application and competition. 1999. 
[24] NorazuraAilaMohdHassim , NurHaqim Ismail, Noor LidaHabi Mat Dayan .Journal of oil palm Research 30(4), 537-547, 2018

[25] Shimpei Watanabe, Shinichi Yoshikawa ,Kiyotaka Sato. Food Chemistry 339, 127808,2020.

[26] Norazura Alia MohdHassim, LNHM Dian.Journal of Oil Palm Research 29(3),301-310, 2017

[27] MHA Jaharul, ISM Zaidul, NAN Norulaini, F Sahena, S Jinap, J Azmir, K M Sharif, AK Mohd Omar

[28] Kevin W Smith , Structured and modified lipids, 401-422, 2001.

[29] BinduNaik , V Kumar . J bioresourceEngTechnol 2 , 1-11, 2014

[30] OF Osundahunsi MK Bolade AA Akinbinu . Journal of Applied Sciences 7(12), 1674-1678, 2007

[31] MK Chang G Abraham, VT John. Journal of the American Oil Chemists Society 67 (11), 832-834,1990

[32] M Lipp, C Simoneau, F Ulberth, E Anklam , C Crews ,P Brereton ,Wim De Greyt,WSchwack, C Wiedmaier.

[33] Yukitaka Tanaka, Yuichi Irinatsu, Aiko Noguchi , Takashi Kobayashi.

[34] Paul S Dimick, Douglas M Manning . Journal of the American Oil Chemist's Society 64(12), 1663-1669, 1987.

[35] Nadia Brunello, Sara E McGauley, AlejendroMarangoni.

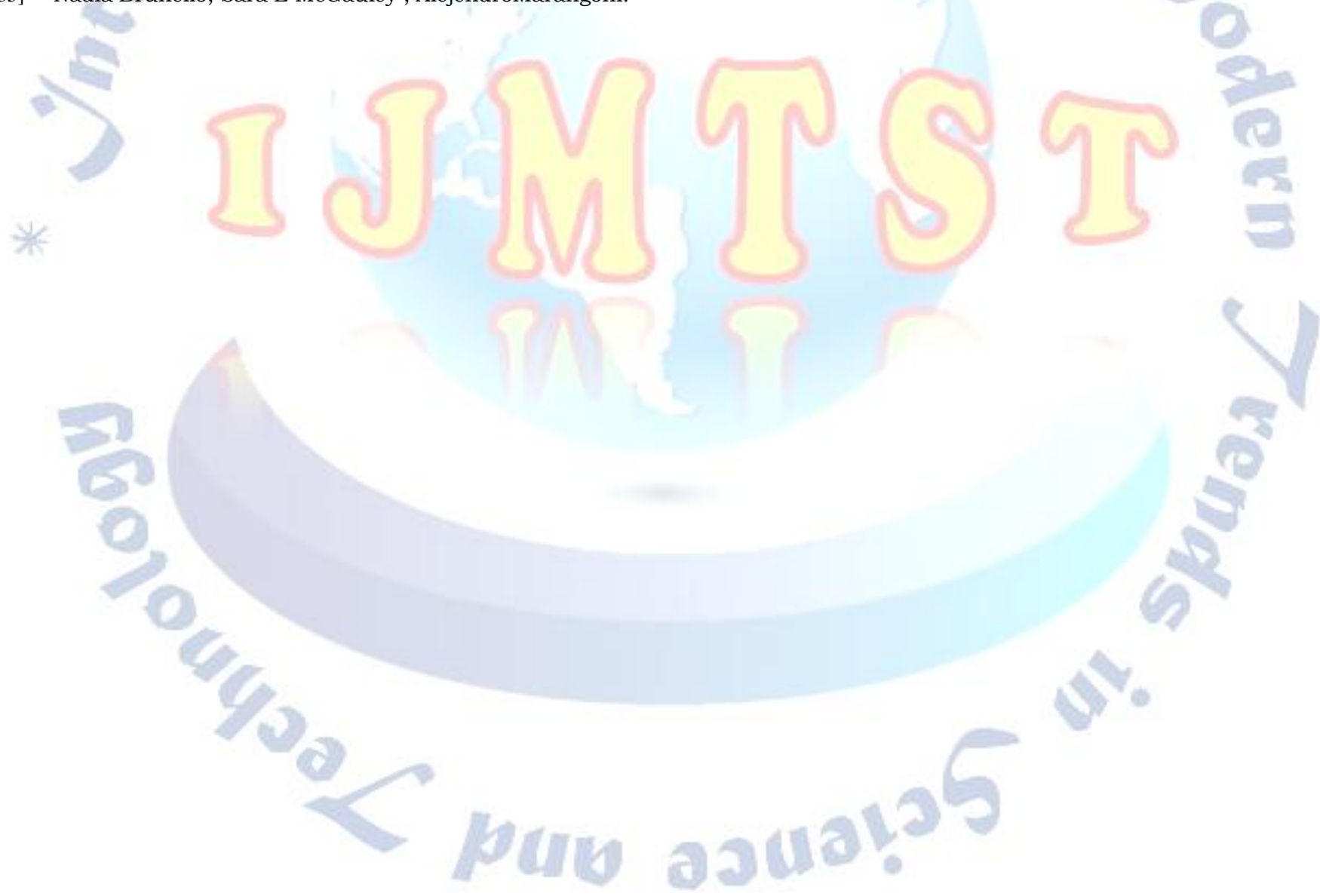

